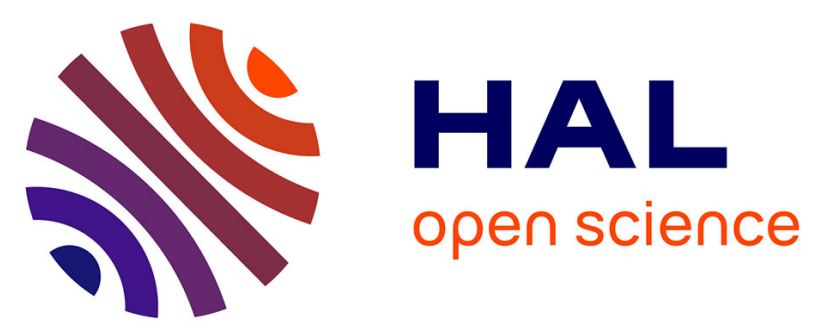

\title{
Structural determinants of resveratrol for cell proliferation inhibition potency: experimental and docking studies of new analogs.
}

Frédéric Mazué, Didier Colin, Jessica Gobbo, Maria Wegner, Antonio Rescifina, Carmela Spatafora, Dominique Fasseur, Dominique Delmas, Philippe Meunier, Corrado Tringali, et al.

\section{To cite this version:}

Frédéric Mazué, Didier Colin, Jessica Gobbo, Maria Wegner, Antonio Rescifina, et al.. Structural determinants of resveratrol for cell proliferation inhibition potency: experimental and docking studies of new analogs.. European Journal of Medicinal Chemistry, 2010, 45 (7), pp.2972-80. 10.1016/j.ejmech.2010.03.024 . hal-00512371

\section{HAL Id: hal-00512371 \\ https://hal.science/hal-00512371}

Submitted on 30 Aug 2010

HAL is a multi-disciplinary open access archive for the deposit and dissemination of scientific research documents, whether they are published or not. The documents may come from teaching and research institutions in France or abroad, or from public or private research centers.
L'archive ouverte pluridisciplinaire HAL, est destinée au dépôt et à la diffusion de documents scientifiques de niveau recherche, publiés ou non, émanant des établissements d'enseignement et de recherche français ou étrangers, des laboratoires publics ou privés. 


\title{
Structural determinants of resveratrol for cell proliferation inhibition potency: experimental and docking studies of new analogs
}

Mazué Frédéric, Colin Didier, Gobbo Jessica, Wegner Maria, Rescifina Antonio ${ }^{\circ}$, Spatafora Carmela $^{\circ \circ}$, Fasseur Dominique $^{\circ}$, Delmas Dominique, Meunier Philippe ${ }^{\circ}$, Tringali Corrado ${ }^{\circ \circ}$, Latruffe Norbert**

INSERM U 866; University of Burgundy, Laboratory of Biochemistry of Metabolism and Nutrition, 6, Bd Gabriel, F-21000 Dijon France

${ }^{\circ}$ ICMUB-UMR CNRS 5260, University of Burgundy, Institute of Molecular Chemistry, Ave Savary, F-21000 Dijon France

${ }^{\circ}$ Università degli Studi di Catania, Dipartimento di Scienze Chimiche, Viale Andrea Doria 6, I-95125 Catania, Italy

** Corresponding author latruffe@u-bourgogne.fr

\begin{abstract}
Resveratrol is the subject of intense research because of the abundance of this compound in the human diet and as one of the most valuable natural chemopreventive agents. Further advances require new resveratrol analogs be used to identify the structural determinants of resveratrol for the inhibition potency of cell proliferation by comparing experimental and docking studies. Therefore, we synthesized new trans / (E)- and cis / (Z)resveratrol - analogs not reported to date - by modifying the hydroxylation pattern of resveratrol and a double bond geometry. We included them in a larger panel of 14 molecules, including (Z)-3,5,4'-trimethoxystilbene, the most powerful molecule that is used as reference. Using a docking model complementary to experimental studies on the proliferation inhibition of the human colorectal tumor SW 480 cell line, we show that methylation is the determinant substitution in inhibition efficacy, but only in molecules bearing a $Z$ configuration. Most of the synthetic methylated derivatives ( $E$ or $Z$ ) stop mitosis at the M phase and lead to polyploid cells, while (E)-resveratrol inhibits cells at the S phase. Docking studies show that almost all
\end{abstract}


of the docked structures of $(Z)$-polymethoxy isomers, but not most of the $(E)$-polymethoxy isomers substantially overlap the docked structure of combretastatin A-4, taken as reference ligand at the colchicin-tubulin binding site.

Key words: Resveratrol, polymethoxy-stilbenes, tubulin polymerization, colon cancer, docking studies.

\section{Introduction}

Recent evidence suggests that the use of resveratrol, a well-known polyphenol that is abundant in the human diet, in combination with drugs, ionizing radiation, or cytokines can be effective in the sensitization to apoptosis. Natural trans-resveratrol [(E)-3,5,4'trihydroxystilbene] targets a wide variety of intracellular mechanisms involved in the pathways leading to malignancy. In various in vitro and in vivo models, this polyphenolic compound has proven to be capable of retarding or preventing the various steps of carcinogenesis [1]. This protective effect could be related to the ability of resveratrol to arrest cell cycle progression [2,3] or to trigger tumor cell death by apoptosis [4, 5]. Recently, resveratrol has been shown to behave also as a sensitizer of anticancer drugs such as 5-fluorouracil [6] and paclitaxel [7], radiation [8], and cytokines such as TRAIL [5].

Nevertheless, various studies have documented that stilbenes and flavonoids, despite efficient absorption by the organism, unfortunately have low bioavailability, glucuronidation and sulfation being limiting factors [9-11]. We have recently developed acetylated forms of resveratrol and oligomers, showing that acetylation of resveratrol inhibits cancer cell proliferation in the same manner as resveratrol [12-14]. In contrast, the isomerization of molecules and the methylation of hydroxyl groups change the cell molecular targets and are essential to strengthen the efficiency of resveratrol derivatives for blocking the cell cycle [1517], suggesting that polymethoxy-stilbenes and related compounds are a subgroup of resveratrol analogs showing promising antitumor properties (see for review [18]). In addition, in vivo studies indicate that polymethoxy-stilbenes undergo a different metabolic conversion and have a higher bioavailability than resveratrol.

While previous studies already reported the synthesis of polymethoxy-stilbene analogs [18], especially highlighting (Z)-3,5,4'-trimethoxystilbene, which exhibits strong antiproliferative activity by acting as an inhibitor of tubulin polymerization [19], the structure-activity relationship remains unclear, for example, the methyl position and number, 
double bond configuration, or the additional hydroxyl group. The originality of our work is based on two strategies: synthesis of three new resveratrol analogs as yet unpublished (compounds 6, 10 and 14) and the use of docking modeling studies and their comparison with experimental data from the human colorectal tumor SW 480 cell line to identify biological targets. For a coherent approach to critical methylation resveratrol analogs and for a better understanding, we tested a larger panel of molecules from already published resveratrol analogs including (Z)-3,5,4'-trimethoxystilbene (compound 4), the most powerful molecule. Thus, with a proper synthetic methodology, previously employed for some of the compounds reported here [20] and exemplified in Fig. 1, a library of resveratrol analogs was obtained from (E)- and (Z)-resveratrol (Fig. 1, compounds 1 and 2). Both (E)- and (Z)- isomers for each substrate were prepared. In the first group, the 3,5,4'-hydroxyl groups of resveratrol were replaced with methoxy groups (compounds 3 and 4) and a further hydroxyl group was inserted at position 2 (compounds 5 and 6); a second group was represented by 3,5,3',5'tetramethoxy-stilbenes (compounds 7 and 8) also bearing an hydroxyl group in C-2 (compounds 9 and 10); in a third group of 3,5,3',4'-tetramethoxy-stilbenes, the two rings were asymmetrically substituted (compounds $\mathbf{1 1}$ and 12), and also in this case the 2-hydroxy analogs were prepared (compounds 13 and 14). We established that the number of methyl groups of resveratrol is crucial for determining the inhibitory properties of colorectal cancer cell proliferation and in cell cycle arrest. The strongest effect depends on Z-stereochemistry. The presence of a supplementary hydroxyl group decreases the efficiency of the antiproliferative properties of resveratrol analogs. Interestingly, $(Z)$-isomer treatments lead to a polyploidy phenomenon in colon cancer cells. Using a computational docking approach, we show that Z-isomers, apart from (Z)-resveratrol and (Z)-tetramethoxy-stilbene, can be incorporated into the colchicine site of tubulin. All $(Z)$-isomers substantially overlap the docked structure of combretastatin A-4 (15), taken as reference.

\section{Material and methods}

\subsection{General}

The ${ }^{1} \mathrm{H}$ and ${ }^{13} \mathrm{C}$ NMR spectra were run on a Varian Unity Inova spectrometer at 500 and 125 $\mathrm{MHz}$, respectively, in $\mathrm{CDCl}_{3}$ or $\mathrm{C}_{6} \mathrm{D}_{6}$ solutions with TMS as internal standard. Mass spectra were recorded in ESI positive mode on a Micromass ZQ2000 spectrometer (Waters). All reactions were monitored by TLC on commercially available precoated plates (silica gel $60 \mathrm{~F}$ 254) and the products were visualized with cerium sulfate solution. A silica gel 60 was employed for column chromatography. Resveratrol (1) was purchased from Sigma; m- 
chloroperbenzoic acid ( $m$-CPBA) 99\% assay was obtained by washing the commercial $77 \%$ material (Aldrich) with a phosphate buffer at $\mathrm{pH} 7.5$ and drying the residue under reduced pressure.

A<smiles>[R]c1cc(Br)cc(/C=C/c2cc([2H])c(Br)c([2H])c2)c1</smiles>

$1 R_{1}=R_{2}=R_{4}=O H ; R_{3}=R_{5}=R_{6}=H$

$3 R_{1}=R_{2}=R_{4}=O C H_{3} ; R_{3}=R_{5}=R_{6}=H$

$5 \mathrm{R}_{1}=\mathrm{R}_{2}=\mathrm{R}_{4}=\mathrm{OCH}_{3} ; \mathrm{R}_{3}=\mathrm{R}_{5}=\mathrm{H} ; \mathrm{R}_{6}=\mathrm{OH}$

$7 R_{1}=R_{2}=R_{3}=R_{5}=O C H_{3} ; R_{4}=R_{6}=H$

$9 \mathrm{R}_{1}=\mathrm{R}_{2}=\mathrm{R}_{3}=\mathrm{R}_{5}=\mathrm{OCH}_{3} ; \mathrm{R}_{4}=\mathrm{H} ; \mathrm{R}_{6}=\mathrm{OH}$

$11 \mathrm{R}_{1}=\mathrm{R}_{2}=\mathrm{R}_{3}=\mathrm{R}_{4}=\mathrm{OCH}_{3} ; \mathrm{R}_{5}=\mathrm{R}_{6}=\mathrm{H}$

$13 \mathrm{R}_{1}=\mathrm{R}_{2}=\mathrm{R}_{3}=\mathrm{R}_{4}=\mathrm{OCH}_{3} ; \mathrm{R}_{5}=\mathrm{H} ; \mathrm{R}_{6}=\mathrm{OH}$

B

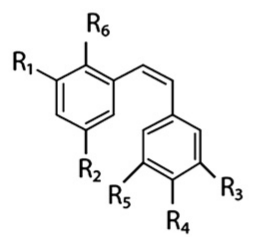

C

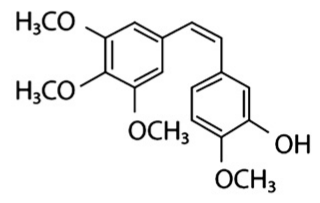

$2 R_{1}=R_{2}=R_{4}=O H ; R_{3}=R_{5}=R_{6}=H$

$4 R_{1}=R_{2}=R_{4}=O C H_{3} ; R_{3}=R_{5}=R_{6}=H$

$6 R_{1}=R_{2}=R_{4}=O_{C H} ; R_{3}=R_{5}=H ; R_{6}=O H$

$8 \mathrm{R}_{1}=\mathrm{R}_{2}=\mathrm{R}_{3}=\mathrm{R}_{5}=\mathrm{OCH}_{3} ; \mathrm{R}_{4}=\mathrm{R}_{6}=\mathrm{H}$

$10 R_{1}=R_{2}=R_{3}=R_{5}=\mathrm{OCH}_{3} ; R_{4}=H ; R_{6}=\mathrm{OH}$

$12 R_{1}=R_{2}=R_{3}=R_{4}=O C H_{3} ; R_{5}=R_{6}=H$

$14 \mathrm{R}_{1}=\mathrm{R}_{2}=\mathrm{R}_{3}=\mathrm{R}_{4}=\mathrm{OCH}_{3} ; \mathrm{R}_{5}=\mathrm{H} ; \mathrm{R}_{6}=\mathrm{OH}$

Fig. 1. Structure of (E)/trans-resveratrol (A), (Z)/cis-resveratrol (B) related analogs and combretastatin A-4 (C)

The known compounds $3, \mathbf{5}, \mathbf{7}, \mathbf{9}, \mathbf{1 1}$, and 13 were synthesized as previously reported, based on an Arbuzov rearrangement followed by the Horner-Emmons-Wadsworth reaction [19]. Compound 4 was prepared by the classic Wittig reaction: 4-methoxybenzyltriphosfonium chloride was reacted with 3,5-dimethoxybenzaldehyde and BuLi in THF to afford 4. Spectral data of the known compounds are in perfect agreement with those obtained previously [17]. Calculated $\log \mathrm{D}$ values were obtained with ACD/labs Log D program version 11.

\subsection{Photo-isomerization}

Irradiation experiments were conducted in a 200-mL quartz vessel using a Rayonet photochemical reactor equipped with a variable number of "black light" phosphor lamps with emission in the $310-$ to $390-\mathrm{nm}$ range and a maximum at $350 \mathrm{~nm}$. The fluence rate at the irradiation position was measured to be $5 \mathrm{~mW} / \mathrm{cm}^{2}$. A $2 \times 10^{-4} \mathrm{M}$ solution $(200 \mathrm{~mL})$ of each compound $(\mathbf{1}, \mathbf{3}, \mathbf{7}$, and $\mathbf{1 1})$ in ethanol was irradiated in the reactor for $10 \mathrm{~min}$ under nitrogen 
bubbling. The irradiated solution was then reduced to a small volume under vacuum and charged onto the appropriate silica gel column to separate the $(Z)$ - product from the residual (E)- isomer. All photo-isomerizations were obtained with $78-82 \%$ conversion, based on ${ }^{1} \mathrm{H}$ NMR measurements. Spectral data of the 2, 4, 8, and 12 compounds obtained are in perfect agreement with those previously reported [17, 21-23].

\subsection{Chemical procedure of hydroxylation}

The compounds 6, 10, and 14 were synthesized as follow: a solution of $m$-CPBA in $\mathrm{CH}_{2} \mathrm{Cl}_{2}$ $(0.150 \mathrm{mmol} / \mathrm{mL})$ was added to a stirred solution of the substrate in $\mathrm{CH}_{2} \mathrm{Cl}_{2}(0.105 \mathrm{mmol} / \mathrm{mL})$ at room temperature. The reaction mixtures were then washed with a $\mathrm{NaHSO}_{3}$ solution and subsequently with saturated aqueous $\mathrm{NaHCO}_{3}$. The organic layer was dried $\left(\mathrm{Na}_{2} \mathrm{SO}_{4}\right)$, filtered, and concentrated in vacuo; the residues were submitted to flash-chromatography on a $3 \times 25-\mathrm{cm}$ silica gel column, eluted with EtOAc in $n$-hexane (from $0 \%$ to $30 \%$ ).

(Z)-2-Hydroxy-3,5,4'-trimethoxystilbene (6): EI-MS m/z, $285[\mathrm{M}-\mathrm{H}]^{-} ;{ }^{1} \mathrm{H}$ NMR $\left(\mathrm{CDCl}_{3}\right): \delta$ $3.53\left(\mathrm{~s}, 3 \mathrm{H}, 4^{\prime}-\mathrm{OCH}_{3}\right) ; 3.77\left(\mathrm{~s}, 3 \mathrm{H}, 5-\mathrm{OCH}_{3}\right) ; 3.86\left(\mathrm{~s}, 3 \mathrm{H}, 3-\mathrm{OCH}_{3}\right) ; 5.35(\mathrm{~s}, 1 \mathrm{H}, \mathrm{OH}) ; 6.33$ (d, $1 \mathrm{H}, \mathrm{J}=2.0 \mathrm{~Hz}, \mathrm{H}-4) ; 6.38(\mathrm{~d}, 1 \mathrm{H}, \mathrm{J}=2.0 \mathrm{~Hz}, \mathrm{H}-6) ; 6.57(\mathrm{~d}, 1 \mathrm{H}, \mathrm{J}=12.0 \mathrm{~Hz}, \mathrm{H}-\alpha) ; 6.61(\mathrm{~d}$, $1 \mathrm{H}, \mathrm{J}=12 \mathrm{~Hz}, \mathrm{H}-\beta) ; 6.75\left(\mathrm{~d}, 2 \mathrm{H}, \mathrm{J}=7.5 \mathrm{~Hz}, \mathrm{H}-3^{\prime}\right.$ and $\left.\mathrm{H}-5^{\prime}\right) ; 7.23\left(\mathrm{~d}, 2 \mathrm{H}, \mathrm{J}=7.5 \mathrm{~Hz}, \mathrm{H}-2^{\prime}\right.$ and H-6'). ${ }^{13} \mathrm{C} \mathrm{NMR}\left(\mathrm{CDCl}_{3}\right): \delta$ 158.7, 152.4, 147.0, 137.6, 130.4, 128.6, 127.4, 123.5, 122.9, $114.2,100.5,98.8,56.2,55.9,55.5$.

(Z)-2-Hydroxy-3,5,3',5'-tetramethoxystilbene (10): EI-MS $\mathrm{m} / \mathrm{z} 315$ [M-H] ${ }^{-}$; ${ }^{1} \mathrm{H}$ NMR $\left(\mathrm{CDCl}_{3}\right): \delta 3.52\left(\mathrm{~s}, 3 \mathrm{H}, 5-\mathrm{OCH}_{3}\right) ; 3.65\left(\mathrm{~s}, 6 \mathrm{H}, 3^{\prime}, 5^{\prime}-\mathrm{OCH}_{3}\right) ; 3.86\left(\mathrm{~s}, 3 \mathrm{H}, 3-\mathrm{OCH}_{3}\right) ; 5.38(\mathrm{~s}$, 1H, OH); 6.31 (s, 1H, H-4'); 6.33 (s, 1H, H-6); 6.37 (s, 1H, H-4); 6.47 (s, 2H, H-2' and H-6'); $6.60(\mathrm{~d}, 1 \mathrm{H}, \mathrm{J}=12.5 \mathrm{~Hz}, \mathrm{H}-\alpha) ; 6.71(\mathrm{~d}, 1 \mathrm{H}, \mathrm{J}=12.5 \mathrm{~Hz}, \mathrm{H}-\beta) .{ }^{13} \mathrm{C} \mathrm{NMR}\left(\mathrm{CDCl}_{3}\right): \delta 159.8$, 153.9, 146.9, 139.2, 137.2, 131.0, 123.9, 122.5, 104.2, 100.0, 99.1, 56.1, 55.7, 55.4.

(Z)-2-Hydroxy-3,5,3',4'-tetramethoxystilbene (14): EI-MS $m / z, 315 \quad[\mathrm{M}-\mathrm{H}]^{-}$; ${ }^{1} \mathrm{H}$ NMR $\left(\mathrm{CDCl}_{3}\right): \delta 3.35\left(\mathrm{~s}, 3 \mathrm{H}, 4^{\prime} \mathrm{OCH}_{3}\right) ; 3.63\left(\mathrm{~s}, 3 \mathrm{H}, 3^{\prime}-\mathrm{OCH}_{3}\right) ; 3.85\left(\mathrm{~s}, 6 \mathrm{H}, 3,5-\mathrm{OCH}_{3}\right) ; 5.36(\mathrm{~s}, 1 \mathrm{H}$, $\mathrm{OH}) ; 6.35$ (d, 1H, J = 2.5 Hz, H-4); 6.38 (d, 1H, J = 2.5 Hz, H-6); 6.59 (bs, 2H, H- $\alpha$ and H- $\beta$ ); $6.74(\mathrm{~d}, 1 \mathrm{H}, \mathrm{J}=8.5 \mathrm{~Hz}, \mathrm{H}-3) ; 6.85\left(\mathrm{~d}, 1 \mathrm{H}, \mathrm{J}=8.5, \mathrm{H}-2^{\prime}\right)$ overlapped with 6.74 (d, 1H, J = 2 $\left.\mathrm{Hz}, \mathrm{H}-6{ }^{\prime}\right) .{ }^{13} \mathrm{C}$ NMR $\left(\mathrm{CDCl}_{3}\right): \delta 151.9,150.1,149.8,148.2,137.6,130.6,129.9,123.7$, $122.1,121.1,111.7,110.7,104.3,98.9,56.2,55.7,55.5,55.4$.

The spectral data of already published resveratrol analogues are in agreeent with those reported in the literature [24]. 


\subsection{Biological methods}

\subsubsection{Proliferation and cytotoxicity assays}

The human colon carcinoma cell line SW480 was cultured in RPMI-Medium with $10 \%$ fetal bovine serum and $1 \%$ antibiotics. Proliferation inhibition assays were performed in 24-well plates in triplicate, and each experiment was conducted three times. In all, 30,000 cells were seeded per well and after $24 \mathrm{~h}$ were treated with media containing either $0.1 \%$ dimethylsulfoxide with (E)-resveratrol, or with resveratrol derivatives, or with $0.1 \%$ dimethylsulfoxide as control. After 24, 48, and $72 \mathrm{~h}$, adherent cells collected by trypsinization and detached cells were labeled in $1 \mathrm{~mL}$ medium containing $1 \mu \mathrm{g} / \mathrm{mL}$ of propidium iodide. Cells were counted using a Cyflow green flow cytometer (Partec, Münster). Dead cells were distinguished from viable cells by incorporation of propidium iodide. Subsequently, 48-h $\mathrm{IC}_{50}$ values were determined by performing $1 \mathrm{nM}$ to $100 \mu \mathrm{M}$ treatments and the $\mathrm{IC}_{50}$ values were obtained after parametric regressions on the percentages of viable cells versus the control.

\subsubsection{Cell cycle and DNA content analysis and . microscopic examination of cell nuclei} morphology. See the techniques previously used in [12-14].

\subsection{Computational docking studies}

In view of the structural similarities of $(Z)$-polymethoxy-stilbenes with combretastatin, we also investigated the binding model of all $(E)$ - and $(Z)$-isomers 1-14 in comparison with combretastatin A-4 to delineate their structure-activity relationships (SARs). Thus, given that the cytotoxicity mechanism of combretastatin and related structures has been shown to involve the inhibition of tubulin polymerization by binding tubulin at the colchicin binding site [25], we conducted molecular docking simulations of all stilbene analogs into this pocket [26]. The reported 3D structure of the tubulin-DAMA-colchicin-stathmin-like domain complex was retrieved from the Protein Data Bank $(<<\mathrm{http}: / /$ www.rcsb.org/PDB $>>$ code $1 \mathrm{SAO})$, but it has a resolution of only $3.58 \AA$ and therefore requires considerable computational effort before models derived from it can be considered "all-atom" [27]. Thus, the stathmin-like domain, the $\mathrm{C}$ and D subunits, and the DAMA-colchicine were removed from the model, the missing atoms on chain A residues Gln 35, Asp 47, Thr 51, Glu 55, Thr 56, Glu 77, Arg 221, Gln 285, Arg 308, Ile 335, Lys 336, Lys 338, Arg 339, Gln 342, and chain B residues His 37, Asn 59, Lys 124, Ser 126, Arg 215, Lys 218, Leu 219, Arg 322, Lys 326, Lys 338, Arg 369, Lys 372, Asp 437 were added and locally optimized. Then, using the 
MolProbity Web server [28], the hydrogen atoms were added and the orientations of the hydroxyl hydrogens from the Ser, Thr, and Tyr, the sulfhydryl orientations of Cys, and the methyls of Met amino acids were optimized; at the same time the positions of hydrogens on histidine, asparagine, and glutamine residues were assigned, ensuring suitable ionization states. Finally, the Gasteiger-Marsili charges [29] were assigned and the whole protein, with the combretastatin A-4 positioned in the place of the DAMA-colchicin ligand and aligned with the A-ring, and the tree methoxyl groups were optimized to an energy gradient of 0.005 kcal- $\AA$ /mol with amber 96 force field [30].

\section{Results}

We compared the potency of resveratrol synthetic analogs toward the human colorectal tumor cell line SW480 by comparing two reference natural molecules, i.e., (E)-3,5,4'Trihydroxystilbene (1) and (Z)-3,5,4'-Trihydroxystilbene (2) (Fig. 1); the (E)- and (Z)isomers of the 3,5,4'-Trimethoxystilbene ( $\mathbf{3}$ and $\mathbf{4}$, respectively), permethylated analogs of resveratrol, were also included in view of their previously reported high antiproliferative activity.

\subsection{Antiproliferative activity toward SW 480 colon cancer cell line}

To compare the effect of resveratrol analogs on cell growth, SW480 cells were treated with molecules from our library and the antiproliferative activity of compounds 1-14 was determined as $\mathrm{IC}_{50}$ (in $\mu \mathrm{M}$ ) and is reported in Table 1. The most active compounds, in order of decreasing potency, were the following: (Z)-3,5,4'-Trimethoxystilbene (4), $0.3 \mu \mathrm{M}>(Z)-2$ Hydroxy-3,5,3',5'-Tetramethoxystilbene (10), $7 \mu \mathrm{M}>(Z)-3,5,3^{\prime}, 4^{\prime}-$ Tetramethoxystilbene (12), 9.5 $\mu \mathrm{M}>$ (Z)-2-Hydroxy-3,5,3',4'-Tetramethoxystilbene (14), $10 \mu \mathrm{M}>(Z)-3,5,3^{\prime}, 5^{\prime}-$ Tetramethoxystilbene (8), $13 \mu \mathrm{M}>(E)$-2-Hydroxy-3,5,3',5'-Tetramethoxystilbene (9), $17 \mu \mathrm{M}$ $>(E)$-Resveratrol (1), $20 \mu \mathrm{M}$.

When compound $\mathbf{1 1}$ was compared with $\mathbf{7}$ (which is only different in the position of one methoxy group) it appeared to be less active. The same tendency was observed between $(E)$ tetramethoxy derivatives, i.e., 13 compared with 9. For the derivatives with trans configuration, too, a slightly higher effect was seen with a methoxy group in another position $(\mathbf{1 2}>\mathbf{8}, 10>14)$. (Z)-3,5,3',4'-Tetramethoxystilbene (12) and (Z)-2-Hydroxy-3,5,3',4'tetramethoxystilbene (14), two $(Z)$-tetramethoxy stilbenes, were potent but they appeared to be less effective than the $(Z)$-trimethoxy analog $\mathbf{4}$ as a reference of the most potent resveratrol 
analog.

\subsection{Cell cycle and DNA content}

To further explore the mechanisms by which all these polyphenols exert their antiproliferative potencies, we studied their effects on the cell cycle distribution of SW480 cells. As shown in the top panel of Fig. 2A, percentages of cells were determined by electronic gating on cell populations according to their DNA content: the diploid cell cycle was divided into a $2 \mathrm{n}$ $\mathrm{G}_{0} / \mathrm{G}_{1}$ phase, an $\mathrm{S}$ phase of DNA replication $(2<\mathrm{n}<4)$, and a $4 \mathrm{n}_{2} / \mathrm{M}$ phase. Moreover, it should be noted that cancer cells, mainly colon cancer cells, are usually unstable and display $>4 n$ DNA content associated with polyploidy. Figure 2A shows the flow cytometry diagrams obtained after 48-h treatments of SW480 cells with all the compounds from our library at 30 $\mu \mathrm{M}$, a common concentration used to evaluate $(E)$-resveratrol anticancer potencies in vitro. Only compound 4 , which is highly toxic at $30 \mu \mathrm{M}$, was used at $1 \mu \mathrm{M}$ for comparison. The synthetic histograms of the cell distribution in the different phases of the cell cycle are also shown in Fig. 2B.

\section{Table 1}

Potencies of resveratrol derivatives antiproliferative activities toward SW480 human colorectal cells after $48 \mathrm{~h}$ of treatment.

\begin{tabular}{|c|c|c|}
\hline Compound & Number & $\mathrm{IC}_{50}(\mu \mathrm{M})$ \\
\hline 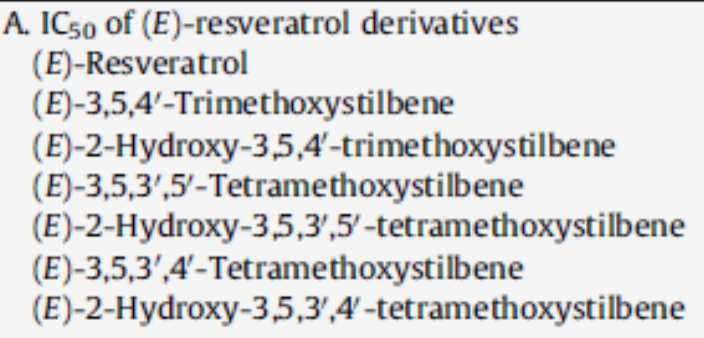 & $\begin{array}{r}1 \\
3 \\
5 \\
7 \\
9 \\
11 \\
13\end{array}$ & $\begin{aligned} 20 & \pm 3 \\
54 & \pm 8 \\
43 & \pm 6 \\
48 & \pm 7 \\
17 & \pm 2 \\
100 & \pm 15 \\
42 & \pm 3\end{aligned}$ \\
\hline 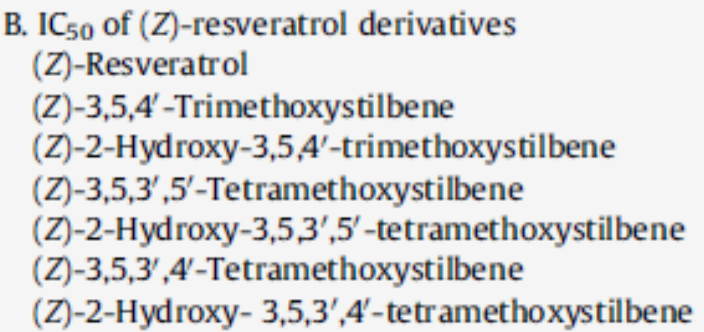 & $\begin{array}{r}2 \\
4 \\
6 \\
8 \\
10 \\
12 \\
14\end{array}$ & $\begin{aligned} 90 & \pm 12 \\
0.3 & \pm 0.04 \\
18 & \pm 2 \\
13 & \pm 2 \\
7 & \pm 2 \\
9.5 & \pm 2 \\
10 & \pm 2\end{aligned}$ \\
\hline
\end{tabular}



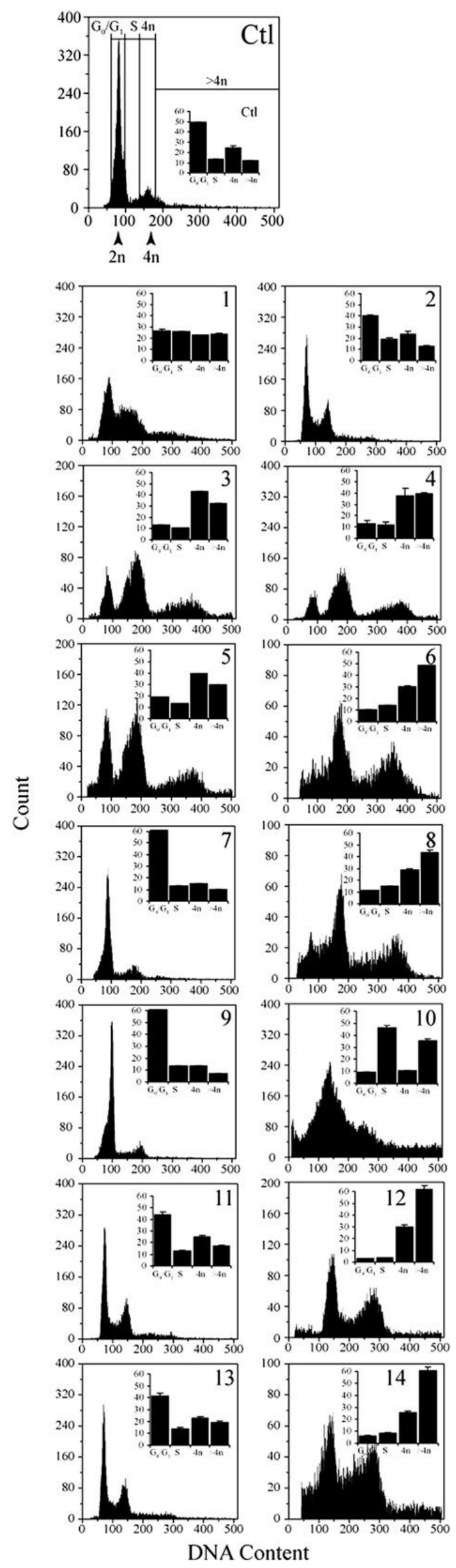

Fig. 2. Effect of methoxyresveratrol analogs on SW480 cell cycle. Flow cytometry analysis of SW480 cells distribution in the cell cycle after $48 \mathrm{~h}$ treatments by resveratrol analogues (number). Diagrams show cell numbers against DNA content measurement by propidium iodide staining. Synthetic histograms of cell distribution among their cell cycle. Data are means +- SD of a representative experiment among

three independent. For experimental procedure, see material and methods. 
Three types of compounds can be reported, according to their effects on cell cycle distribution: those that exert no effects and are essentially $(E)$-isomers plus $(Z)$-resveratrol (compounds $2,7,9,11,13$ ) with an average of $50 \% \mathrm{G}_{0} / \mathrm{G}_{1}$ cells, $15 \% \mathrm{~S}$ cells, $25 \% 4 \mathrm{n}$ cells, and $10 \%>4 \mathrm{n}$ cells. Another compound is the well-known $(E)$-resveratrol by itself, which induces a strong S-phase arrest and a small increase of polyploidy. Finally, many compounds (especially $(Z$ )-isomers, compounds $3, \mathbf{4}, \mathbf{5}, \mathbf{6 , 8}, \mathbf{1 0}, \mathbf{1 2}, \mathbf{1 4}$ ) completely disturb the diploid cell cycle, leading to the generation of polyploid cells, more precisely of tetraploid cells because of the loss of $2 n$ cells and of the increase in $4 n$ and $8 n$ cells.

To have an overall view of the mechanisms involved in the polyploidization induced by most of the (Z)-isomers, we performed a time- and concentration-dependent analysis of the effects of (Z)-3,5,4'-trimethoxystilbene (4) as reference [19]. The antiproliferative activity of this compound occurred in a time- and dose-dependent manner as compared to $(E)$-resveratrol, and did not exert toxic effects at the highest concentration used $(1 \mu \mathrm{M})$ (Fig. 3A). It was also noted that in contrast to $(E)$-resveratrol, there was no growth resurgence after $72 \mathrm{~h}$. Moreover, at $1 \mu \mathrm{M}\left(\mathrm{IC}_{50}=0.3 \mu \mathrm{M}\right)$, compound 4 did not seem to be more potent than $0.2 \mu \mathrm{M}$ or $0.5 \mu \mathrm{M}$. Thus, cell cycle analyses after treatment with the same concentrations showed comparable results: $0.5 \mu \mathrm{M}$ and $1.0 \mu \mathrm{M}$ treatments led to exactly the same profile of cell cycle disruption with an increase of $4 \mathrm{n}$ and $>4 \mathrm{n}$ cells (Fig. 3B). Nevertheless, $0.2-\mu \mathrm{M}$ treatments exerted weaker effects than higher concentrations with regard to cell distribution in the cell cycle.

We then used microscopic analysis to illustrate the accumulation of polyploid cells after treatment with compound 4 (Fig. 3). Hoechst staining allowed us to confirm that this (Z)isomer leads to mitotic disturbances. Indeed, as compared to resveratrol treatment, which induces nuclear swelling, compound 4 inhibits cytokinesis resulting in endocycle and multinucleated cells (karyokinesis inhibition would have produced giant nuclei). 

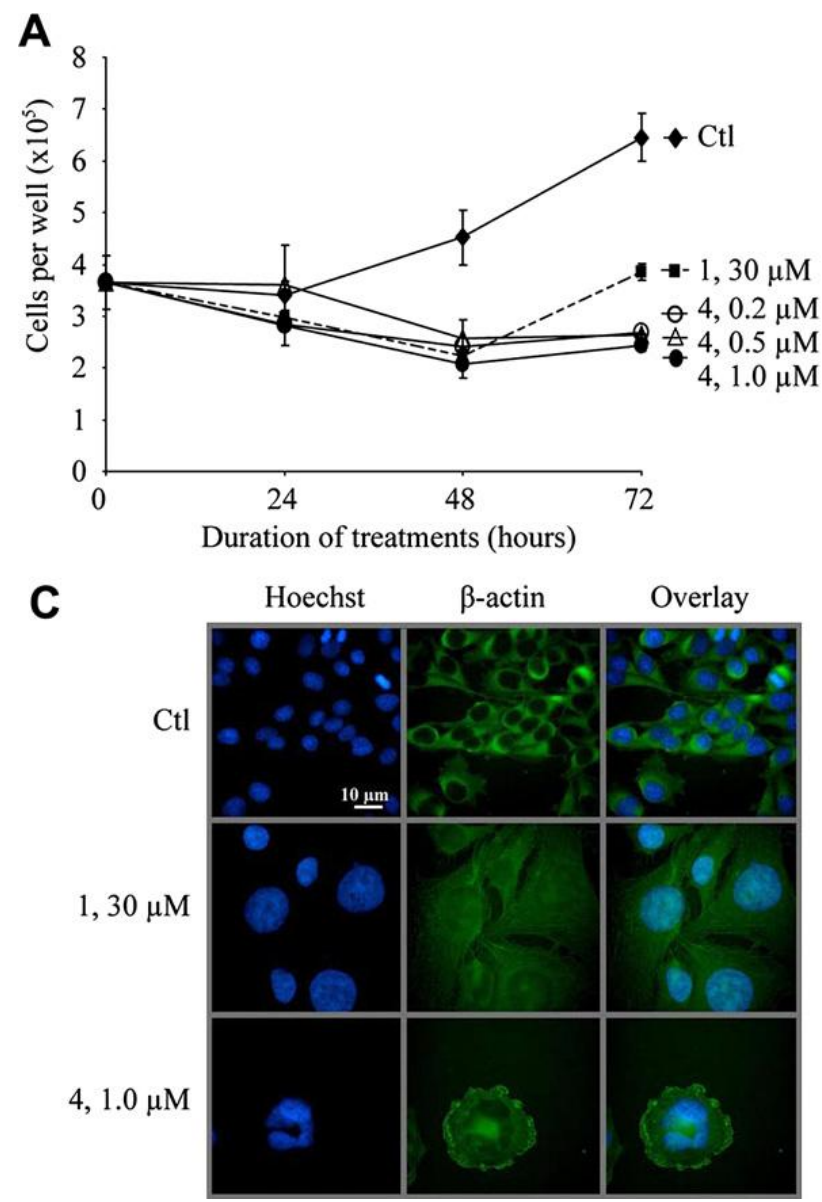

B

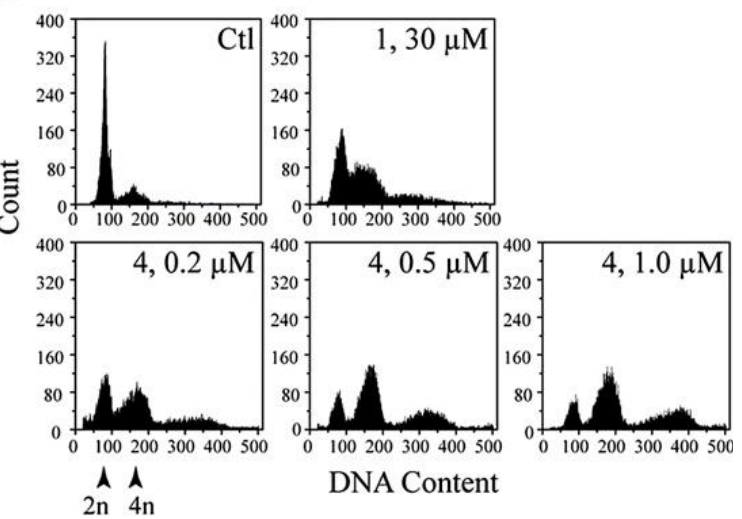

Fig. 3. Inherent mechanisms of antiproliferative activity of compound 4. A. Proliferation of SW480 cells treated with resveratrol (compound 1) at $30 \mu \mathrm{M}$ and compound 4 from 0.2 to $1.0 \mu \mathrm{M}$ during 24, 48 and $72 \mathrm{~h}$. Data are means +- SD of a representative experiment among three independent. For experimental procedure, see material and methods. B. Flow cytometry analysis of SW480 cells distribution in the cell cycle after $48 \mathrm{~h}$ treatments by compound 1 and 4 at indicated concentrations. Diagrams show cell numbers against DNA content measurement by propidium iodide staining. C. Microscopic analysis of SW480 cells left untreated (Ctl) or treated with $30 \mu \mathrm{M}$ resveratrol (1) or with $0.5 \mu \mathrm{M}$ of compound 4 for $48 \mathrm{~h}$. Green fluorescence (Alexa 488) is due to actin immunostaining performed to see the shape of the cells. Blue fluorescence (Hoechst 33342) reveals nuclei. All the pictures have been taken with the same conditions and magnification (100x). This figure represents an example of three independent experiments. [For interpretation of the references to colour in this figure legend, the reader is referred to the web version of this article.]

\subsection{Binding model of $(E)$ - and (Z)- stilbene isomers}

Starting from the experimental data (presented in previous sections), we looked for possible relationships between structures of resveratrol analogs and their affinity to bind colchicine at the tubulin binding site, responsible for mitosis inhibition and polyploidy, via a computational docking approach.

To validate the model, we docked combretastatin A-4 (Fig. 1) and some structurally diversified combretastatin-like analogs that bind to colchicin at the tubulin binding site to compare their experimentally obtained $\mathrm{IC}_{50}$ values with the calculated values. The results obtained (not reported here; see Supplementary Data) showed that the model is able to reproduce the $\mathrm{IC}_{50}$ experimental values with a high precision that is, to our knowledge, the 
best obtained to date by docking methodology. The model was applied successively to compounds 1-14 and the results obtained, arranged in order of decreasing calculated activity, are presented in Table 2.

\begin{tabular}{|c|c|c|}
\hline Ligand & $\Delta G_{\text {and }}$ calcd. ( $\left.\mathrm{kcal} / \mathrm{mol}\right)$ & $\mathrm{IC}_{\text {so }} \mathrm{cal}$ al. $(\mu \mathrm{M})$ \\
\hline 10 & -7.87 & 1.69 \\
\hline 6 & -7.72 & 2.18 \\
\hline 12 & -7.53 & 3.00 \\
\hline 4 & -7.50 & $3.16^{4}$ \\
\hline 2 & -7.27 & 4.66 \\
\hline 1 & -7.24 & 4.90 \\
\hline 14 & -7.14 & 5.80 \\
\hline 9 & -7.01 & 7.23 \\
\hline 7 & -7.01 & 7.23 \\
\hline $\mathbf{8}$ & -6.93 & 8.27 \\
\hline 3 & -6.82 & 9.96 \\
\hline 5 & -6.79 & 10.48 \\
\hline 11 & -6.72 & 11.79 \\
\hline 13 & -6.46 & 18.30 \\
\hline
\end{tabular}

* An experimental value of 400 is reported. See Schneider et al. [19].

Although almost all the $(E)$-isomers were less active than the $(Z)$-isomers against the inhibition of SW480 cells, they were integrated into the colchicine site of tubulin. Moreover, compounds 1, 7, and 9 showed a binding affinity comparable to that of compounds $\mathbf{1 4}$ and $\mathbf{8}$; these data point out that the efficiency in the interaction with the receptor site, alone, is not sufficient to elucidate the anticancer potency, and many other factors, such as adsorption, distribution, and metabolism, must be considered especially important in this case. However, some conclusions can be made from the docking results. All docked structures of (Z)-isomers, with the exception of compound $\mathbf{2}$, which is moved down, and compound $\mathbf{8}$, which is overturned, substantially overlap the docked structure of combretastatin A-4, taken as reference (Fig. 4A). Moreover, compounds 6 and 14 collocated the 3,5-dimethoxy groups of the A-ring in the same position of the corresponding combretastatin A-4 rings with the hydroxylic moiety, which engages a hydrogen bond with Ser B132 (not shown); conversely, compound 10, which possesses the best affinity, has two $m$-methoxy groups in both the Aand B-rings so it could be arranged into two possible orientations with respect to combretastatin A-4. The best arrangement results from the B-ring overlapping with the A-ring of compound 15, as shown in Fig. 4B. In this position, compound $\mathbf{1 0}$ establishes six hydrogen bonds with the tubulin receptor: 3'-methoxyl with the Cys B238 sulfhydryl, 5'-methoxyl with 
the Ser A132 hydroxyl, 2-hydroxyl with both carbonyl of Thr A133 and Asn B255, and 3methoxyl with the Lys A67 ammonium and with Ala A134 amidic hydrogen (Fig. 4B). Finally, Fig. 4C shows how all (E)-isomers overlap compared with combretastatin A-4. Also, in this case all compounds are sufficiently aligned between them but not with combretastatin, with the exception of compounds $\mathbf{3}$ and $\mathbf{5}$, which, possessing only one methoxyl in the B-ring, prefer to interact with the hydrophobic channel that joins the A and B subunits protruding to the A subunits. Interestingly, the three compounds with the 2-hydroxyl group are almost perfectly overlapping with the B-ring of the reference compound combretastatin.
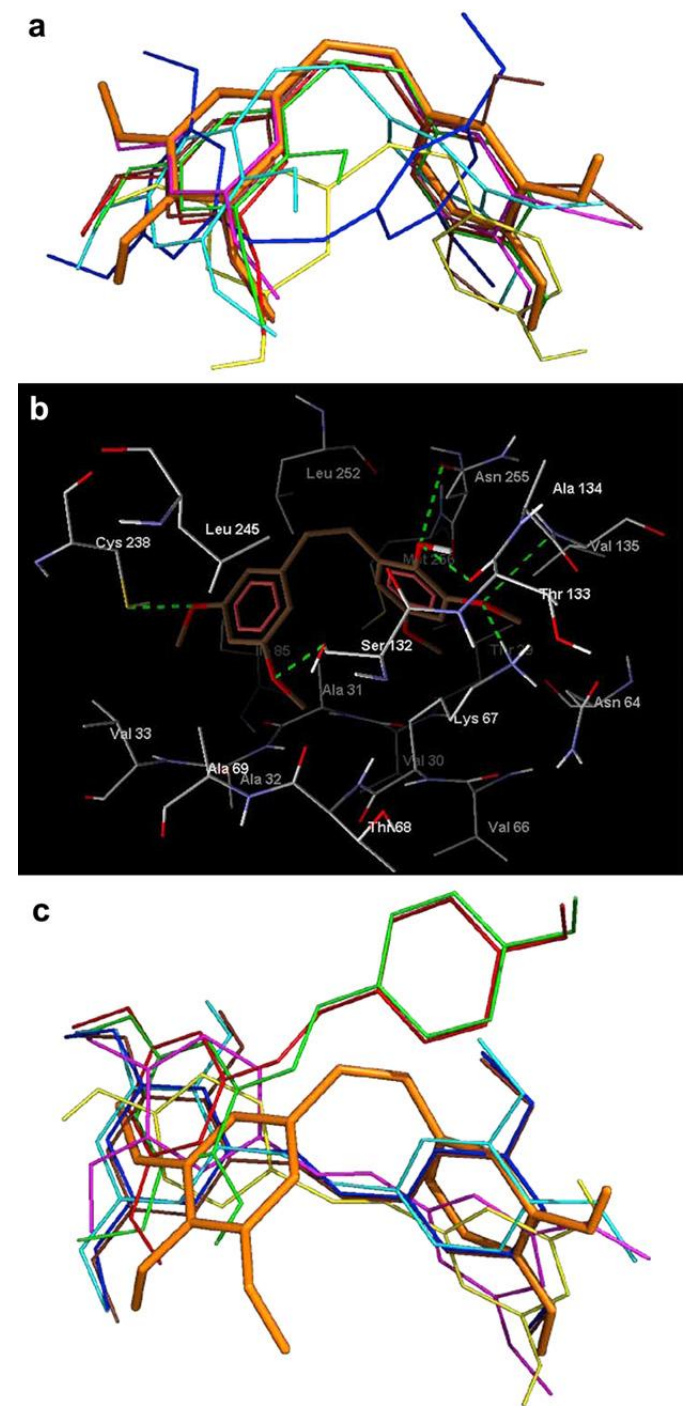

Fig. 4. Computational studies and bindingmodel of (E)- and (Z)-stilbenes isomers. For part $\mathrm{A}$ and $\mathrm{C}$, the binding models for all stilbenes were constructed using the combretastatin model [25] as a template and reference ligand in the binding site. Computational docking was carried out applying the Lamarckian genetic algorithm (LGA) implemented in Auto-Dock 4.0 [29]. For fine docking, we used the following parameters: grid spacing $=0.261 \AA$, number of runs $=100$, npts $=50-60-50$ centered on combretastatin A-4, ga_num_ evals $=20,000,000$, ga_pop_size $=150$, and ga_num_generations $=27,000$. A. Superposition of all $(Z)$-stilbene analogues docked at the colchicine-binding site. The docked structure of combretastatin A-4, represented in orange (tube rendering), is inserted for comparison. Only polar hydrogens are represented, for clarity. Ligands are rendered as 
sticks with the subsequent colour code: 2 yellow, 4 red, 6 green, 8 blue, 10 brown, 12 magenta and 14 cyan. B.Moleculardockingresultof compound10 at the colchicine-binding site of tubulin.Only theamino acid residueswithin 4.5 Aaround the inhibitor are shownfor clarity. The ligand is represented with the carbon skeleton in brown with the only polar hydrogen. Dotted lines represent hydrogen bonds between ligand and receptor. The numerotation of amino acid residues is decremented by 3 unit for subunit $A$ and 56 for subunit $B$ respect to the original PDB file due to the strongmanipulation and multiple file format conversions experienced. C. Superposition of all (E)-stilbene analogues docked at the colchicine-binding site. The docked structure of combretastatin A-4, represented in orange (tube rendering), is inserted for comparison. Only polar hydrogens are represented, for clarity. Ligands are rendered as sticks with the subsequent colour code: 1 yellow, 3 red, 5 green, 7 blue, 9 brown, 11 magenta and 13 cyan. [For interpretation of the references to colour in this figure legend, the reader is referred to the web version of this article.]

The comparison between binding models of $(E)$ - and $(Z)$-resveratrol isomers with regard to tubulin and cell proliferation inhibition potencies is presented in Table 3, with the following results:

- Almost all the (Z)-polymethoxy stilbenes were more active than the $(E)$-polymethoxy stilbenes. One exception may occur for compound $\mathbf{9}$, but the difference is within the SD range of compound 6. Conversely, $(E)$-resveratrol (1) is significantly more active than $(Z)$ resveratrol (2) notwithstanding that both showed a similar affinity for the tubulin pocket (similar $\mathrm{IC}_{50}$ values calculated from docking). These data are in agreement with our previous assumptions [15], i.e., that the mechanism of the antiproliferative activity of resveratrol seems to be different from that of polymethoxy stilbenes, the latter probably being related to inhibition of tubulin.

- Among (Z)-polymethoxy stilbenes, 3,5,4'-trimethoxystilbene (4) is confirmed to be the most active compound by far. This result is also in perfect agreement with the data of Schneider et al. [19], who reported an $\mathrm{IC}_{50}=0.23 \mu \mathrm{M}$ versus SW480 cells for 4. This is partly in agreement with our docking results, indicating that compound $\mathbf{4}$ integrated well within the tubulin hydrophobic pocket but with a lower score than compounds 6, 10, and 12 . Nevertheless, 6 was (relative to 4) scarcely hydrophobic (see calculated $\log$ D values) and this could explain the difference between tubulin fitting and in vitro activity: scarcely hydrophobic compounds (like resveratrol itself) could not reach the hydrophobic pocket of tubulin, regardless of their docking "score." Compound $\mathbf{4}$ was also more hydrophobic than $\mathbf{1 0}$ and $\mathbf{1 2}$, and this is probably an important factor to target the tubulin site. Both compounds $\mathbf{6}$ and $\mathbf{1 0}$ were hydroxylated at C-2 and this structural detail seems important for tubulin fitting, but is probably an unfavorable factor in bioassays, perhaps because of easier metabolic conversion or air oxidation. It is known from the literature that $\mathbf{1}$ has a rapid metabolic conversion [31]. Compound 12 is probably in an intermediate situation, i.e., it has less tubulin affinity but it may be less sensitive to degradation. 
- Compounds $\mathbf{8}$ and $\mathbf{1 4}$ were in a similar range of activity, which was partly confirmed by the docking data (Table 3). Analogously, the group of (E)-polymethoxy stilbenes with lower activity $\left(\mathbf{3}, \mathbf{5}, \mathbf{7}, \mathbf{1 1}, \mathbf{1 3}\right.$; experimental $\mathrm{IC}_{50}$ values: $\left.42-100 \mu \mathrm{M}\right)$ do not fit well with the tubulin pocket (calculated $\mathrm{IC}_{50}$ values: $7-18 \mu \mathrm{M}$ ).

\begin{tabular}{|c|c|c|c|}
\hline Compound ${ }^{x}$ & $\begin{array}{l}\text { Calculated tubulin } \\
\mathrm{K}_{20}(\mu \mathrm{M})^{\mathrm{s}}\end{array}$ & $\begin{array}{l}\text { Experimental } \\
\mathrm{KC}_{20} \text { range values }(\mu \mathrm{M})\end{array}$ & Calaulated $\log D$ \\
\hline 10 & 169 & $5-9$ & 388 \\
\hline 6 & 2.18 & $16-20$ & 356 \\
\hline 12 & 300 & $7.5-11.5$ & 398 \\
\hline 4 & 3.16 & $0.26-0.34$ & 4.32 \\
\hline 2 & 466 & $78-102$ & 302 \\
\hline 1 & 490 & $17-23$ & 302 \\
\hline 14 & 580 & $8-12$ & 323 \\
\hline 9 & 723 & $15-19$ & 388 \\
\hline 7 & 723 & $41-55$ & 464 \\
\hline 8 & 827 & $11-15$ & 464 \\
\hline 3 & 996 & $46-62$ & 431 \\
\hline 5 & 10.48 & $37-49$ & 356 \\
\hline 11 & 11.79 & $85-115$ & 398 \\
\hline 13 & 18.30 & $39-45$ & 323 \\
\hline
\end{tabular}

\section{Discussion}

We compared two series of molecules starting from $(E)$-stereoisomer and its $(Z)$-counterpart. It must be noted that to date the use of $(Z)$-resveratrol has not been reported. Some of the compounds tested demonstrate much more potencies than the natural parent molecule. Compared with $(E)$-resveratrol, which leads to a cell growth arrest in S phase, the methylated derivatives stop cell proliferation by inducing $\mathrm{G}_{2} / \mathrm{M}$ failures and also a polyploidization of the SW480 cell line. (E)-resveratrol derivatives also induce cancer cell apoptosis since sub- $\mathrm{G}_{1}$ peaks were found during the flow cytometry analysis.

Cell polyploidization, which can occur naturally to repair damaged DNA, is induced by all of the methylated compounds. (Z)-3,5,4'-trimethoxystilbene (4) has been described as an inhibitor of tubulin polymerization [1931]. Inhibition leads to a mitosis defect and cytokinesis impairment. The destiny of tetraploidy-induced cells is unknown; these cells could still proliferate and become more resistant [32] or die by mitotic catastrophe [33].

The study of synthetic $(E)$-resveratrol derivatives could offer a wide range of compounds that are potentially more active than $(E)$-resveratrol (about 66-fold for 4), but these molecules seem to have a different way of delaying cancer cell growth.

Our team previously tested similar resveratrol analogs on various tumor cell lines: DU-145 
(androgen-nonresponsive human prostate cancer), LNCaP (androgen-responsive human prostate cancer tumor), M-14 (human melanoma), and KB (human mouth epidermoid carcinoma) [15]. In all cell lines, results indicate a stronger effect of (E)-3,5,4'trimethoxystilbene (3) than (E)-resveratrol, especially toward DU-145 cells. The corresponding ( $Z$ )-trimethoxy analog 4 was very active toward the KB cell line but with a poor effect on M-14 cells.

Szekeres's group [34] reported on the influence of several $(E)$-resveratrol analogs on HT 29 human colon cancer cell proliferation inhibition and apoptosis, and some results are similar to those obtained by our group, i.e., the poor effect of $(E)-3,5,3^{\prime}, 4^{\prime}$-tetramethoxystilbene $(\mathbf{1 1})$ and blockade on $\mathrm{G}_{0}-\mathrm{G}_{1}$. Other results are conflicting; a strong effect of (E)-3,5,4'trimethoxystilbene (3) on HT 29 cells and a weaker effect on SW480 cells (our data).

More generally, methylated resveratrol analogs, although nonantioxidant molecules, have a stronger effect than the parent molecule. Indeed, they inhibit the human tumor necrosis factor alpha-induced activation of transcription factor nuclear factor kappa B [35].

In summary, while $(E)$-resveratrol is considered to be a promising molecule for fighting cancer [36], synthetic resveratrol analogues could offer a wide range of compounds that are potentially more active than $(E)$-resveratrol. These molecules seem to have a different way of delaying cancer cell growth. Resveratrol inhibits cells in S phase, while most of the other synthetic derivatives stop mitosis or block it in an unknown manner $(\mathbf{7}, \mathbf{9}, \mathbf{1 1}, \mathbf{1 3})$. We can consider that these methylated derivatives, which are prevented from any hydroxyl groupconjugation dependency, would be less metabolized than resveratrol and potentially more bioavailable. Indeed, we have observed (unpublished results) limited metabolism of $\mathbf{4}$ after incubation with the SW480 cell line. Moreover, recent results from Lin and Ho $[37,38]$ are in agreement with this statement, since they reported that the pharmacokinetics of $(E)-3,5,4^{\prime}-$ trimethoxystilbene (3) and (E)-3,5,3'4'-tetramethoxystilbene (11) in rat plasma are much slower than those of $(E)$-resveratrol, i.e., greater plasma exposure, longer elimination exposure, and lower clearance. In addition, the stronger effect of $(Z)$-methoxy derivatives with respect to their $(E)$-isomers is not related to the lack of an antioxidative effect (disappearance of hydroxyl groups) but is probably due to a steric-dependent mechanism leading to interference in different pathways as compared to the trans derivatives.

We learned of the recent work of Li et al., [39], while our work was just being completed and submitted. This work reports the effect of a pentamethoxy resveratrol derivative and the analysis of its apoptotic properties. Although from our respective analogs the (Z)-methoxy 
derivatives have both microtubule targets, our present paper does not have the same objective since our goal was the analysis of a structure-function relationship using a large series of analog (E)- and (Z)-derivatives, especially by combining experimental data and an original docking approach. Moreover, in our cell model and molecules we did not detect a strong apoptosis but a strong polyploidy (see Fig. 2).

With regard to the docking work, it is noteworthy that the adopted procedure, consisting in the extrusion of colchicin from the tubulin binding site, reconstruction of protein deficiencies (lacking in amino acid residues, hydrogen bondings, hydrogen orientations, etc.), restoring the appropriate ligand (combretastatin A-4), molecular mechanic minimization of the whole system, and, finally, submission to the AutoDock docking program [40], allowed us to obtain a model that was able to reproduce the $\mathrm{IC}_{50}$ experimental values of other combretastatin analogs also reported in the literature with a high grade of precision that is, to our knowledge, the best obtained to date using docking methodology. Although the results obtained do not always coincide with the antitumoral activity, this is probably attributable to the ADME implications and not to the mechanism of actions. Then the described procedure results in a new valid approach for determining a potential tubulin ligand in the colchicin binding site.

\section{Conclusions}

1- The relatively weak effect of $(E)$-RSV is not exclusively attributable to its high metabolic rate and efflux, since the masking of hydroxyl groups by methylation does not significantly improve the resveratrol analog efficacy;

2- The $Z$ configuration does not enhance resveratrol efficacy since its potency is weaker than that of the isomer with the $E$ configuration;

3- In contrast to the preceding statement (\#2), the $Z$ configuration associated with the substitution of hydroxy groups by methoxy groups is crucial and leads to potent inhibition efficacy;

4- Following the preceding statement (\#3) the strong efficacy of the (Z)-3,5,4'trimethoxystilbene $\mathbf{4}$ would also be associated with the molecule's poor cell metabolism; 
5- The presence of more than three methoxyl groups on the (Z)-resveratrol core structure does not enhance resveratrol analog efficacy but rather gives it a weaker effect;

6- The presence of a new hydroxyl group on tri-methylated (Z)-resveratrol analogs dramatically decreases the inhibitory potency;

7- Concerning the inhibitory mechanism, the presence of methoxy groups, whichever resveratrol isomer $(E)-,(Z)$ - is considered, induces cell polyploidy resulting from the blockade of cell divisions at the mitosis level;

8- The relationship between spatial conformations of resveratrol analogs and their effect fits quite well with docking studies where almost all of the docked structures of $(Z)$-polymethoxy isomers overlap substantially with the docked structure of combretastatin A-4 (15), taken as reference ligand, to bind at the colchicine-tubulin binding site, while most of the $(E)$ polymethoxy isomer counterparts fit between them but not with combretastatin.

\section{Conflict of interest statement}

The authors have no conflict of interest to declare.

\section{Acknowledgements}

This study was supported by BIVB, the Regional Council of Burgundy, the Cancer League of Côte d'Or and Jura, INSERM U866, CNRS, UMR 5260, MIUR, Ministero dell'Università e della Ricerca (PRIN 2007, Rome, Italy), and Università degli Studi di Catania, (PRA, Catania, Italy). We thank Mrs Linda Northrup for improvement of the English.

\section{References}

[1] Jang M, Cai L, Udeani GO, Slowing KV, Thomas CF, Beecher CW, et al. Cancer chemopreventive activity of resveratrol, a natural product derived from grapes. Science.275 (1997)218-20.

[2] Delmas D, Passilly-Degrace P, Jannin B, Malki MC, Latruffe N. Resveratrol, a chemopreventive agent, disrupts the cell cycle control of human SW480 colorectal tumor cells. Int J Mol Med.10 (2002)193-9.

[3] Delmas D, Jannin B, Malki MC, Latruffe N. Inhibitory effect of resveratrol on the proliferation of human and rat hepatic derived cell lines. Oncol Rep.7@82000) 47-52. 
[4] Delmas D, Rebe C, Lacour S, Filomenko R, Athias A, Gambert P, et al. Resveratrolinduced apoptosis is associated with Fas redistribution in the rafts and the formation of a death-inducing signaling complex in colon cancer cells. J Biol Chem.278(2003) 1482-90.

[5] Delmas D, Rebe C, Micheau O, Athias A, Gambert P, Grazide S, et al. Redistribution of CD95, DR4 and DR5 in rafts accounts for the synergistic toxicity of resveratrol and death receptor ligands in colon carcinoma cells. Oncogene.23(2004) 8979-86.

[6] Fulda S, Debatin KM. Sensitization for anticancer drug-induced apoptosis by the chemopreventive agent resveratrol. Oncogene. 23 (2004)6702-11.

[7] Jazirehi AR, Bonavida B. Resveratrol modifies the expression of apoptotic regulatory proteins and sensitizes non-Hodgkin's lymphoma and multiple myeloma cell lines to paclitaxel-induced apoptosis. Mol Cancer Ther.3(2004)71-84.

[8] Zoberi I, Bradbury CM, Curry HA, Bisht KS, Goswami PC, Roti Roti JL, et al. Radiosensitizing and anti-proliferative effects of resveratrol in two human cervical tumor cell lines. Cancer Lett. 2002175 (2002)165-73.

[9] Xu X, Wang HJ, Murphy PA, Cook L, Hendrich S. Daidzein is a more bioavailable soymilk isoflavone than is genistein in adult women. J Nutr.124 (1994) 825-32.

[10] Hollman PC, van Trijp JM, Buysman MN, van der Gaag MS, Mengelers MJ, de Vries $\mathrm{JH}$, et al. Relative bioavailability of the antioxidant flavonoid quercetin from various foods in man. FEBS Lett.418 (1997) 152-6.

[11] Lee MJ, Wang ZY, Li H, Chen L, Sun Y, Gobbo S, et al. Analysis of plasma and urinary tea polyphenols in human subjects. Cancer Epidemiol Biomarkers Prev.4 (1995)393-9.

[12] Colin D, Gimazane A, Lizard G, Izard JC, Solary E, Latruffe N, et al. Effects of resveratrol analogs on cell cycle progression, cell cycle associated proteins and 5fluoro-uracil sensitivity in human derived colon cancer cells. Int J Cancer.124 (2009)2780-8.

[13] Colin D, Lancon A, Delmas D, Lizard G, Abrossinow J, Kahn E, et al. Antiproliferative activities of resveratrol and related compounds in human hepatocyte derived HepG2 cells are associated with biochemical cell disturbance revealed by fluorescence analyses. Biochimie.90 (2008)1674-84.

[14] Marel AK, Lizard G, Izard JC, Latruffe N, Delmas D. Inhibitory effects of transresveratrol analogs molecules on the proliferation and the cell cycle progression of human colon tumoral cells. Mol Nutr Food Res.52 (2008)538-48.

[15] Cardile V, Chillemi R, Lombardo L, Sciuto S, Spatafora C, Tringali C. Antiproliferative activity of methylated analogues of $\mathrm{E}$ - and Z-resveratrol. Z Naturforsch C.62 (2007)189-95.

[16] Roberti M, Pizzirani D, Simoni D, Rondanin R, Baruchello R, Bonora C, et al. Synthesis and biological evaluation of resveratrol and analogues as apoptosis-inducing agents. J Med Chem. 46 (2003)3546-54.

[17] Pettit GR, Grealish MP, Jung MK, Hamel E, Pettit RK, Chapuis JC, et al. Antineoplastic agents. 465. Structural modification of resveratrol: sodium resverastatin phosphate. J Med Chem.45 (2002)2534-42.

[18] Chillemi R, Sciuto S, Spatafora C, Tringali C. Anti-tumor properties of stilbene-based resveratrol analogues: recent results. Nat Prod Commun.2 (2007)1-15.

[19] Schneider Y, Chabert P, Stutzmann J, Coelho D, Fougerousse A, Gosse F, et al. Resveratrol analog (Z)-3,5,4'-trimethoxystilbene is a potent anti-mitotic drug inhibiting tubulin polymerization. Int J Cancer.107 (2003)189-96. 
[20] Spatafora C, Basini G, Baioni L, Grasselli F, Sofia A, Tringali C. Antiangiogenic resveratrol analogues by mild m-CPBA aromatic hydroxylation of 3,5dimethoxystilbenes. Nat Prod Commun.4 (2009)239-46.

[21] Deak M, Falk H. On the chemistry of the resveratrol diastereomers. Monatshefte fuer Chemie.134 (2003)883-8.

[22] Momotake, Atsuya, Ud, Mayuko-Arai, Tatsuo. Photochemical cyclisation reaction in cis-tetramethoxystilbene. J Photochem \& Photobiol A Chemistry.158 (2003)7-12.

[23] Gao M, Wang M, Miller K, Sledge G, Hutchins G, Zhang Q. Synthesis of radiolabelled stilbene derivative a new potential PET probe for arylhydrocarbon receptor in cancer. Bio-org Med Chem Lett.16 (2006) 5767-72.

[24] Koh D, Park K H, Jung J, Yang, Mok K H, Lim Y. Spectral Assignments and Reference Data NMR spectra of resveratrol derivatives Complete assignment of the 1H and 13C. Magn Reson Chem 39 (2001): 768-70

[25] Nam NH. Combretastatin A-4 analogues as antimitotic antitumor agents. Curr Med Chem . 10 (2003)1697-722.

[26] Ravelli RB, Gigant B, Curmi PA, Jourdain I, Lachkar S, Sobel A, et al. Insight into tubulin regulation from a complex with colchicine and a stathmin-like domain. Nature.428 (2004)198-202.

[27] Nguyen TL, McGrath C, Hermone AR, Burnett JC, Zaharevitz DW, Day BW, et al. A common pharmacophore for a diverse set of colchicine site inhibitors using a structure-based approach. J Med Chem.48 (2005)6107-16.

[28] Lovell SC, Davis IW, Arendall WB, 3rd, de Bakker PI, Word JM, Prisant MG, et al. Structure validation by Calpha geometry: phi,psi and Cbeta deviation. Proteins.50 (2003) 437-50.

[29] Gasteiger j, Marsili M. A new model for calculating atomic charges in molecules. Tetrahedron Lett.34 (1978)3181-4.

[30] Cornell W, Cieplak P, Bayly C, Gould I, Merz Jr. K, Ferguson D, et al. A Second Generation Force Field for the Simulation of Proteins, Nucleic Acids, and Organic Molecules. J Am Chem Soc.117 (1995) 3-13

[31] Seiler N, Schneider Y, Gosse F, Schleiffer R, Raul F. Polyploidisation of metastatic colon carcinoma cells by microtubule and tubulin interacting drugs: effect on proteolytic activity and invasiveness. Int J Oncol.25 (2004)1039-48.

[32] Erenpreisa J, Kalejs M, Cragg MS. Mitotic catastrophe and endomitosis in tumour cells: an evolutionary key to a molecular solution. Cell Biol Int.29 (2005)1012-8.

[33] Mansilla S, Priebe W, Portugal J. Mitotic catastrophe results in cell death by caspasedependent and caspase-independent mechanisms. Cell Cycle. 5 (2006)53-60.

[34] Saiko P, Pemberger M, Horvath Z, Savinc I, Grusch M, Handler N, et al. Novel resveratrol analogs induce apoptosis and cause cell cycle arrest in HT29 human colon cancer cells: inhibition of ribonucleotide reductase activity. Oncol Rep.19 (2008)16216.

[35] Heynekamp JJ, Weber WM, Hunsaker LA, Gonzales AM, Orlando RA, Deck LM, et al. Substituted trans-stilbenes, including analogues of the natural product resveratrol, inhibit the human tumor necrosis factor alpha-induced activation of transcription factor nuclear factor kappaB. J Med Chem.49 (2006)7182-9.

[36] Baur JA, Sinclair DA. Therapeutic potential of resveratrol: the in vivo evidence. Nat Rev Drug Discov.5 (2006)493-506.

[37] Lin HS, Ho PC. A rapid HPLC method for the quantification of 3,5,4'-trimethoxytrans-stilbene (TMS) in rat plasma and its application in pharmacokinetic study. $\mathrm{J}$ Pharm Biomed Anal.49 (2009)387-92[38] Lin HS, Tringali C, Spatafora C, C. Wu C, Ho PC. A simple and sensitive HPLC-UV method for the quantification of piceatannol 
analog 3,5,3',4'-tetramethoxy-trans-stilbene in rat plasma and its application for a preclinical pharmacokinetic study. J. Pharm. Biomed. Anal. 51 (2010) 679-684.

[39] Li H, Wu WK, Zheng Z, Che CT, Yu L, Li ZJ, Wu YC, Cheng KW, Yu J, Cho CH, Wang M . 2,3',4,4',5'-Pentamethoxy-trans-stilbene, a resveratrol derivative, is a potent inducer of apoptosis in colon cancer cells via targeting microtubules. Biochem Pharmacol.. 78 (2009)1224-32[40] Morris G, Goodsell D, Halliday R, Huey R, Hart W, Belew R, et al. Automated Docking Using a Lamarckian Genetic Algorithm and an Empirical Binding Free Energy Function. J Comput Chem. 19 (1998) 1639-62. 